\title{
ASPECTOS FINANCEIROS RELACIONADOS ÀS PERDAS DE NUTRIENTES POR EROSÃO HÍDRICA EM DIFERENTES SISTEMAS DE MANEJO DO SOLO ${ }^{(1)}$
}

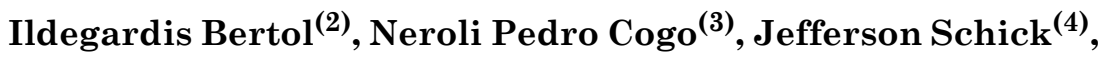 \\ Jean Cláudio Gudagnin ${ }^{(5)}$ \& André Júlio Amaral ${ }^{(6)}$
}

\begin{abstract}
RESUMO
A erosão hídrica é a forma mais séria de degradação do solo, pois, além de reduzir a capacidade produtiva deste para as culturas, causa prejuízos financeiros e ambientais em razão da perda de nutrientes a ela associada. A presente pesquisa foi realizada com o objetivo de quantificar as perdas de água e solo, de $\mathrm{P}, \mathrm{K}, \mathrm{Ca}$ e $\mathrm{Mg}$ na água e de $\mathrm{P}$ disponível e $\mathrm{K}$, Ca e $\mathrm{Mg}$ trocáveis nos sedimentos da enxurrada perdida por erosão hídrica, em um experimento realizado sob chuva natural, entre novembro de 1992 e outubro de 2003, no sul do Planalto Catarinense. Calculou-se o custo financeiro desses nutrientes, expressos na forma de superfosfato triplo (P), cloreto de potássio (K) e de calcário (Ca e Mg), perdidos na erosão hídrica, para um Cambissolo Húmico alumínico léptico com declividade média de $0,10 \mathrm{~m} \mathrm{~m}^{-1}$, em três sistemas de manejo do solo, com duas repetições: preparo convencional (PC), preparo mínimo (PM) e semeadura direta (SD). Em uma das repetições dos tratamentos foram cultivados soja, trigo, milho, ervilhaca, feijão, aveia, soja e nabo forrageiro, em sistema de rotação de culturas, enquanto na outra se cultivaram soja, trigo, soja, trigo, soja, trigo, soja e trigo, em sistema de sucessão de culturas. Para efeito de realização deste trabalho, as duas parcelas experimentais com o mesmo tipo de manejo do solo foram consideradas como repetição, embora com diferentes espécies culturais (em rotação e em sucessão de culturas). As perdas de solo foram fortemente influenciadas pelo sistema de manejo e variaram com os anos de cultivo, enquanto as perdas de água variaram menos do que as de solo, tanto nos sistemas de manejo
\end{abstract}

\footnotetext{
(1) Trabalho desenvolvido com recursos do CNPq/CAPES/UDESC. Recebido para publicação em dezembro de 2005 e aprovado em novembro de 2006.

(2) Professor do Departamento de Solos da Faculdade de Agronomia, Universidade do Estado de Santa Catarina - CAV/UDESC. Caixa Posta 281, CEP 88520-000 Lages (SC). Bolsista do CNPq. E-mail: a2ib@cav.udesc.br

(3) Professor do Departamento de Solos da Faculdade de Agronomia da Universidade Federal do Rio Grande do Sul - UFRGS. Caixa Postal 15100, CEP 90001-970 Porto Alegre (RS). Bolsista do CNPq. E-mail: neroli@ufrgs.br

(4) Professor da Faculdade de Engenharia Florestal da Universidade de Canoinhas - UNC. Canoinhas (SC). E-mail: schick@www.cni.unc.br

(5) Extensionista Rural da EPAGRI. Lages (SC). E-mail: a8jcg@cav.udesc.br

${ }^{(6)}$ Engenheiro-Agrônomo, M.Sc. Ciência do Solo. CAV/UDESC. E-mail: a8aja@cav.udesc.br.
} 
do solo quanto nos anos de cultivo. $O$ valor monetário das perdas anuais de $\mathbf{P}$ expresso na forma de superfosfato triplo, de $\mathrm{K}$ expresso como cloreto de potássio e de Ca e Mg expressos na forma de calcário, por erosão hídrica, foi relativamente elevado, independentemente do sistema de manejo do solo. A SD e o PM comportaram-se de modo semelhante em termos de valor monetário das referidas perdas, em cujos tratamentos as perdas de água e solo foram expressivamente menores que no preparo convencional. O valor monetário da perda anual por hectare de $\mathrm{K}$ expresso na forma de cloreto de potássio, por erosão hídrica, foi equivalente a 2,6 vezes aquele representado pelo somatório das perdas de $\mathbf{P}$ na forma de superfosfato triplo e de $\mathrm{Ca}$ e $\mathrm{Mg}$ na forma de calcário, na média dos sistemas de manejo do solo. Na SD, essas perdas foram de US\$14,83 por hectare por ano, enquanto no PM foram de US\$16,33 e, no PC, de US\$ 24,94. Na média destes sistemas de manejo do solo, o valor monetário total anual por hectare das perdas de $P$ expresso na forma de superfosfato triplo correspondeu a $8,6 \%$, enquanto de K na forma de cloreto de potássio e de Ca e Mg expressos na forma de calcário o valor correspondeu a 76,8 e 14,6\%, respectivamente.

Termos de indexação: custo da erosão, nutrientes na enxurrada, preparo do solo.

\title{
SUMMARY: FINANCIAL ASPECTS OF NUTRIENT LOSSES BY WATER EROSION IN DIFFERENT SOIL MANAGEMENT SYSTEMS
}

\begin{abstract}
Water erosion is the most deleterious form of soil degradation. Besides reducing the production capacity of soils for crops, it causes strong financial and environmental impacts, due to the nutrient losses associated with it. This research work was developed with the objective of quantifying water and soil losses, $\mathrm{P}, \mathrm{K}, \mathrm{Ca}$, and $\mathrm{Mg}$ losses in runoff water and extracted $P$, and exchangeable $\mathrm{K}, \mathrm{Ca}$ and $\mathrm{Mg}$ losses in runoff sediments, caused by rainfall erosion, in an experiment conducted under natural rainfall, in the period from November, 1992 to October, 2003, in the south of the region Planalto Catarinense, in Santa Catarina State, Brazil. The financial value of these nutrients were calculated, expressed in triple phosphate $(P)$, potassium chloride $(K)$, and limestone (Ca and $M g)$, which were lost through water erosion from an Inceptsoil with $0.10 \mathrm{~m} \mathrm{~m}^{-1}$ slope steepness, under the following three different soil management systems: (a) conventional tillage (CT), (b) minimum tillage $(M T)$, and (c) no tillage (NT), in duplication. One of the replications was cultivated with soybean, wheat, corn, vetch, bean, oat, soybean, and fodder radish in a crop rotation scheme, and the other replication cultivated with soybean and wheat in a continuous double-cropping scheme. Particularly for this study, the pair of plots with the same tillage type was considered replicates, regardless of the difference in crop species cultivated in each of them. Unlike water losses, soil losses were strongly influenced by soil tillage systems and crop years. The annual monetary value of losses of triple phosphate $(P)$, potassium chloride $(K)$, and limestone ( $\mathrm{Ca}$ and $\mathrm{Mg}$ ) by erosion were relatively high, regardless of the tillage type. The loss in NT reached U\$14.83 dollars per hectare per year, in MT U\$16.33 per hectare per year and in CT U\$24.94 dollars per hectare per year. Of these tillage methods, the mean annual monetary value loss in triple phosphate $(P)$ fertilizer corresponded to $8.6 \%$, while in terms of potassium chloride $(\mathrm{K})$ fertilizer and limestone (Ca and $\mathrm{Mg}$ ) they corresponded to 76.8 and $14.6 \%$, respectively.
\end{abstract}

Index terms: erosion costs, nutrients in runoff, soil tillage.

\section{INTRODUÇÃO}

A erosão hídrica é influenciada pela chuva, pelo solo, pela topografia, pela cobertura e manejo do solo e por práticas conservacionistas de suporte (Hudson, 1995). Dentre esses fatores, a cobertura e o manejo do solo se constituem no mais importante, já que sua eficácia de redução das perdas de solo por erosão hídrica pode ser quase completa, porém é relativamente menos eficaz e muito variado em relação à redução das perdas de água (Cogo, 1981; Bertol et al., 1997; Schick et al., 2000a), nutrientes e carbono orgânico (Hernani et al., 1997; Seganfredo et al., 1997; Schick et al., 2000b; Bertol et al., 2003). 
O preparo do solo pelo método convencional mobiliza totalmente a superfície e ocasiona rugosidade superficial relativamente elevada, aumentando a porosidade total da camada preparada (Cogo, 1981), e, num curto espaço de tempo, predispõe a superfície do solo ao selamento superficial (Duley, 1939; McIntyre, 1958). Além disso, com o passar do tempo, a rugosidade superficial criada pelo preparo neste sistema de manejo tende a diminuir, reduzindo, conseqüentemente, a capacidade do solo de reter e infiltrar água na superfície, o que aumenta a enxurrada e a erosão hídrica (Cogo, 1981; Bertol et al., 1997; Schick et al., 2000a).

Dentre os sistemas de manejo do solo conservacionista que deixam apreciável quantidade de resíduos culturais na sua superfície, a semeadura direta é o que apresenta maior potencial de redução das perdas de solo por erosão hídrica, podendo, em algumas situações, chegar a valores mínimos (Hernani et al., 1997; Schick et al., 2000a). Isso ocorre devido à ausência de preparo, que permite a manutenção de praticamente todos os resíduos culturais e o aumento da consolidação na superfície do solo, embora ocorra aumento na densidade do solo e redução no volume total de poros, especialmente os macroporos (Bertol et al., 2004a). Em determinadas situações, especialmente sob longos comprimentos de rampa e, ou, maiores inclinações do terreno, além de elevadas perdas de água na forma de enxurrada, as perdas de solo por erosão hídrica também podem ser relativamente elevadas na semeadura direta (Foster et al., 1982; Cogo et al., 1996; Bertol et al., 1997; Morais \& Cogo, 2001).

As perdas de água da chuva na forma de enxurrada geralmente são menos influenciadas pelo efeito da cobertura e manejo do solo do que as perdas de solo (Cogo et al., 1996; Bertol et al., 1997; Morais \& Cogo, 2001; Mello et al., 2003), já que este apresenta capacidade-limite de absorção de água. Ultrapassado tal limite, o excesso de água da chuva escoa, independentemente do sistema de manejo empregado. Isso ocorre especialmente sob chuvas de longa duração, portanto de elevado volume, as quais saturam o solo $\mathrm{e}$, assim, produzem grandes enxurradas.

A concentração de nutrientes na enxurrada da erosão hídrica depende da concentração destes na camada mais superficial do solo, a qual é influenciada pela fertilidade natural e pela quantidade, pelo tipo e pela forma de aplicação dos fertilizantes e corretivos no solo (Schick et al., 2000b; Bertol et al., 2003; Martínez-Casanovas \& Ramos, 2004). Assim, as perdas totais de nutrientes por erosão hídrica são resultantes da concentração destes no solo original e das quantidades totais de solo e água removidas no processo erosivo (Schick et al., 2000b; Favaretto, 2002; Bertol et al., 2003; Guadagnin et al., 2005). Em geral, existe relação linear positiva entre a concentração de nutrientes no material erodido e aquela na camada de $0-2,5 \mathrm{~m}$ de profundidade do solo original (Schick et al., 2000b; Bertol et al., 2003).
Os nutrientes das plantas, como $\mathrm{P}, \mathrm{K}, \mathrm{Ca}$ e $\mathrm{Mg}$, perdidos por erosão hídrica, podem significar expressiva perda monetária, na forma de adubos e calcário que foram adicionados ao solo (Freitas \& Castro, 1983; Pimentel et al., 1995; Alfsen et al., 1996; Martínez-Casanovas \& Ramos, 2004), com conseqüente aumento no custo de produção das culturas. Essas perdas são expressivamente diminuídas, em termos absolutos, na presença de sistemas de manejo conservacionista do solo (Langdale et al., 1985) e de cultivo em contorno (Stoltenberg \& White, 1953), já que estes diminuem a erosão hídrica, e, ainda, com a adoção de terraços agrícolas (MartínezCasanovas \& Ramos, 2004), pois os terraços podem armazenar a enxurrada nos seus canais, dentro das lavouras. As perdas de nutrientes por erosão hídrica podem se constituir em importante causa de empobrecimento do solo no local de origem da erosão e, ainda, de contaminação do ambiente, especialmente as águas superficiais, fora do local de origem da erosão (Daniel et al., 1994; Pimentel et al., 1995; Ibáñez et al., 2004). Assim, quando mantidos dentro das lavouras, tais nutrientes podem representar importante economia em adubos e em calcário no sistema de produção vegetal.

O objetivo do presente trabalho foi avaliar o custo monetário decorrente das perdas de alguns nutrientes das plantas por erosão hídrica, como $\mathrm{P}$ disponível e $\mathrm{K}$, $\mathrm{Ca}$ e $\mathrm{Mg}$ trocáveis, em um Cambissolo Húmico alumínico léptico submetido a diferentes sistemas de manejo.

\section{MATERIAL E MÉTODOS}

Os dados para o presente estudo foram coletados entre novembro de 1992 e outubro de 2003, no sul do Planalto Catarinense, em local situado entre $27^{\circ} 49^{\prime}$ de latitude sul e $50^{\circ} 20^{\prime}$ de longitude, a oeste de Greenwich. O solo é um Cambissolo Húmico alumínico léptico, apresentando horizonte A moderado, substrato composto por siltitos + argilitos e declividade média de $0,10 \mathrm{~m} \mathrm{~m}^{-1}$. O clima da região é do tipo $\mathrm{Cfb}$, segundo a classificação de Köppen, com precipitação média anual em torno de $1.600 \mathrm{~mm}$.

O histórico da área experimental, submetida à chuva natural desde o início dos estudos (1988) até 1992, encontra-se descrito em Schick et al. (2000a, b). No período compreendido entre 1993 e 2003 , foram realizados e avaliados os tratamentos descritos a seguir, com duas repetições.

Os tratamentos de manejo do solo foram efetuados duas vezes ao ano, em duplicata, por ocasião da implantação das culturas de inverno e de verão, consistindo de: (1) preparo convencional - uma aração+duas gradagens (PC), (2) preparo mínimo uma escarificação+uma gradagem (PM); e (3) semeadura direta (SD). Em uma das repetições dos tratamentos de preparo cultivaram-se soja, trigo, 
milho, ervilhaca, feijão, aveia, soja e nabo forrageiro, em sistema de rotação de culturas, enquanto na outra repetição foram cultivados soja, trigo, soja, trigo, soja, trigo, soja e trigo, em sistema de sucessão de culturas. No entanto, tendo em vista as pequenas diferenças observadas nos resultados entre os dois sistemas de cultivo (sucessão e rotação de culturas), as duas unidades experimentais com o mesmo tipo de preparo do solo foram consideradas como repetição. Mais detalhes sobre esses tratamentos podem ser obtidos em Schick et al. (2000a, b) e Bertol et al. (2004a).

Entre 1988 (ano de implantação do experimento) e 2003, a área experimental foi adubada com $630 \mathrm{~kg} \mathrm{ha}^{-1}$ de $\mathrm{N}$ na forma de uréia, $1.527 \mathrm{~kg} \mathrm{ha}^{-1} \mathrm{de}_{2} \mathrm{O}_{5}$ na forma de superfosfato triplo e $1.388 \mathrm{~kg} \mathrm{ha}^{-1} \mathrm{de} \mathrm{K}_{2} \mathrm{O}$ na forma de cloreto de potássio, os quais foram distribuídos nos diversos cultivos realizados desde então. Os adubos foram aplicados a lanço e em cobertura na SD, a lanço e semi-incorporados ao solo no PM e a lanço e incorporados ao solo no PC. Além disso, o solo foi corrigido com calcário dolomítico, na dose de $12 \mathrm{t} \mathrm{ha}^{-1}$, em outubro de 1988 (primeira aplicação) e, em outubro de 1992 (segunda aplicação), houve acréscimo de 3,5 t ha $^{-1}$ do mesmo produto.

A unidade experimental de erosão hídrica constituiu-se de uma parcela com $22,1 \mathrm{~m}$ de comprimento e $3,5 \mathrm{~m}$ de largura, delimitada em sua extremidade superior e nas laterais por chapas galvanizadas, cravadas $0,10 \mathrm{~m}$ no solo, providas de um sistema coletor de enxurrada na sua extremidade inferior. Esse coletor era constituído de uma calha coletora conectada por meio de um tubo de PVC a um conjunto de dois tanques, situados $6 \mathrm{~m}$ abaixo da parcela, onde a enxurrada era armazenada e de onde se coletavam as amostras. O primeiro tanque (de decantação) era conectado ao segundo (de suspensão) por meio de um divisor tipo "Geib", provido de nove aberturas. Assim, apenas 1/9 da enxurrada passava do primeiro para o segundo tanque, através da abertura localizada na posição central do divisor.

As perdas de solo foram determinadas seguindo o procedimento sugerido por Cogo (1978) e ajustadas para a declividade de $0,9 \mathrm{~m} \mathrm{~m}^{-1}$ (declive da parcela-padrão da Equação Universal de Perda de Solo - EUPS), com base no procedimento descrito por Wischmeier \& Smith (1978). Nos sedimentos (fração sólida), separados por decantação da água (fração líquida) de enxurrada, determinaram-se as concentrações de $\mathrm{P}$ disponível e de $\mathrm{K}, \mathrm{Ca}$ e $\mathrm{Mg}$ trocáveis, seguindo o procedimento descrito em Tedesco et al. (1995). Usando o mesmo procedimento, determinaram-se, na água (fração líquida) de enxurrada, as concentrações de $\mathrm{P}, \mathrm{K}, \mathrm{Ca}$ e Mg solúveis. As quantidades totais de $\mathrm{P}, \mathrm{K}, \mathrm{Ca}$ e Mg perdidas por erosão hídrica (incluindo a perda nos sedimentos e na água), em cada chuva que causou erosão, foram obtidas por meio do produto das concentrações desses elementos nos sedimentos e na água com as quantidades de sedimentos e de água perdidas pela erosão hídrica.
As quantidades de $\mathrm{P}, \mathrm{K}$ Ca e Mg perdidas pela erosão hídrica $\left(\mathrm{kg} \mathrm{ha}^{-1} \mathrm{ano}^{-1}\right)$ foram expressas em quantidades de superfosfato triplo (P), cloreto de potássio $(\mathrm{K})$ e calcário $(\mathrm{Ca}+\mathrm{Mg})$, levando-se em conta a porcentagem média de $\mathrm{P}_{2} \mathrm{O}_{5}$ no superfosfato triplo (42 \%), $\mathrm{K}_{2} \mathrm{O}$ no cloreto de potássio (60 \%) e CaO + MgO no calcário dolomítico (38\%). Com base nas quantidades de superfosfato triplo, cloreto de potássio e calcário, os valores das perdas de P, K, Ca e Mg por erosão hídrica foram expressos em US $\$ \mathrm{ha}^{-1} \mathrm{ano}^{-1}$, adotando-se a equivalência US $\$ 1,0=\mathrm{R} \$ 2,50$, num procedimento semelhante ao utilizado por Freitas \& Castro (1983). Para esses cálculos adotou-se, ainda, o valor de US\$ 324,00 para a tonelada de superfosfato triplo, de US\$ 328,00 para a tonelada de cloreto de potássio e de US\$116,20 para a tonelada de calcário dolomítico. O valor do dólar, dos adubos e do calcário foi baseado em preços cotados em 25 de outubro de 2005.

\section{RESULTADOS E DISCUSSÃO}

As perdas de solo foram mais fortemente influenciadas pelos sistemas de manejo do solo do que as de água (Quadro 1), conforme também constatado por Cogo (1981), Bertol et al. (1997) e Schick et al. (2000a). Assim, a semeadura direta reduziu as perdas de solo em 88 \% em relação ao preparo convencional, enquanto as perdas de água foram reduzidas em $57 \%$, na média dos valores anuais, o que confirma que a semeadura direta é muito mais eficaz na redução de perdas de solo do que de água, em relação ao preparo convencional. Esse efeito é explicado pela elevada cobertura do solo por resíduos culturais na semeadura direta, a qual é mais eficaz na dissipação da energia cinética das gotas de chuva, sendo, no entanto, menos eficaz na retenção superficial de água e na dissipação da energia de enxurrada. Isso porque as perdas de água são mais dependentes da capacidade de retenção e infiltração superficiais, as quais são mais relacionadas ao tipo de solo e às condições físicas de superfície deste do que ao sistema de manejo propriamente dito. Portanto, numa condição de solo com $100 \%$ de superfície coberta, é possível reduzir as perdas de solo em $100 \%$, enquanto as perdas de água não são reduzidas na mesma proporção, especialmente sob chuvas de elevado volume e em condições de declive favoráveis ao escoamento (Bertol et al., 1997; Morais \& Cogo, 2001), devido aos limites de capacidade de infiltração e de armazenamento de água do solo, estabelecidos pelo tipo de solo e pelas suas condições físicas.

As perdas de água e solo indicam que o preparo mínimo apresentou comportamento intermediário entre a semeadura direta e o preparo convencional (Quadro 1), conforme também verificado por outros autores (Cogo, 1981; Bertol et al., 1997; Schick et al., 2000a). As variações verificadas nas perdas de água 
Quadro 1. Perdas de água e solo por erosão hídrica, em três sistemas de manejo do solo e 11 anos de cultivo

\begin{tabular}{|c|c|c|c|c|c|c|}
\hline \multirow{2}{*}{ Ano agrícola } & \multicolumn{3}{|c|}{ Água } & \multicolumn{3}{|c|}{ Solo } \\
\hline & $\mathrm{PC}$ & $\mathbf{P M}$ & SD & $\mathbf{P C}$ & PM & SD \\
\hline & \multicolumn{3}{|c|}{$\mathrm{m}^{3} \mathrm{ha}^{-1} \mathrm{ano}^{-1}$} & 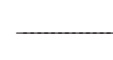 & $\mathrm{ha}^{-1}$ ano & - \\
\hline $1992 / 1993$ & 961 & 1.130 & 1.069 & 3,715 & 1,850 & 0,685 \\
\hline $1993 / 1994$ & 1.518 & 1.031 & 447 & 3,355 & 0,565 & 0,225 \\
\hline $1994 / 1995$ & 111 & 237 & 48 & 0,635 & 1,070 & 0,305 \\
\hline $1995 / 1996$ & 1.393 & 1.067 & 274 & 4,555 & 3,890 & 0,845 \\
\hline $1996 / 1997$ & 5.674 & 2.434 & 2.412 & 2,505 & 1,105 & 0,770 \\
\hline $1997 / 1998$ & 6.503 & 3.518 & 3.335 & 13,150 & 10,345 & 6,115 \\
\hline $1998 / 1999$ & 1.544 & 1.106 & 217 & 20,597 & 2,136 & 0,076 \\
\hline $1999 / 2000$ & 3.411 & 1.666 & 1.372 & 9,918 & 2,482 & 0,798 \\
\hline $2000 / 2001$ & 4.644 & 2.780 & 1.972 & 2,882 & 1,334 & 0,522 \\
\hline $2001 / 2002$ & 2.057 & 1.621 & 796 & 1,625 & 1,477 & 0,858 \\
\hline $2002 / 2003$ & 389 & 283 & 97 & 35,693 & 0,878 & 0,294 \\
\hline Média & 2.564 & 1.534 & 1.094 & 8,966 & 2,466 & 1,045 \\
\hline
\end{tabular}

PC: preparo convencional; PM: preparo mínimo; SD: semeadura direta.

e solo nos anos de cultivo foram normais, principalmente de acordo com as variações no volume das chuvas (para o caso das perdas de água) e suas equivalentes erosividades (para o caso das perdas de solo), cujos dados encontram-se em outros trabalhos realizados na mesma área experimental (Schick et al., 2000a; Guadagnin et al., 2005). Esse comportamento foi dependente, ainda, das variações no teor de água anteriormente contido no solo, nas diferentes culturas e períodos de cultivos estudados.

As concentrações de $\mathrm{P}$ e K na água de enxurrada diferiram entre tratamentos e entre cultivos e foram menores, em especial as de P (Quadro 2), do que as concentrações no solo apresentadas por Schick et al. (2000b) e Bertol et al. (2004) trabalhando no mesmo experimento, enquanto as de $\mathrm{Ca}$ e $\mathrm{Mg}$ na água de enxurrada foram semelhantes às do solo e com menores variações entre tratamentos, também como constatado por esses autores. Na SD, a concentração de P na água de enxurrada foi 3,3 vezes maior do que no preparo convencional, e a de K, 1,8 vez maior, na média dos cultivos; já Schick et al. (2000b) constataram que para o $\mathrm{P}$ essa relação foi de 1,3 vez e, para o K, de 1,7 vez, explicada pela maior concentração deste elemento na superfície do solo na semeadura direta. As variações entre cultivos das concentrações de P, K, Ca e Mg na água de enxurrada foram normais, dependentes das variações dos fatores que influenciaram a mineralização dos elementos, especialmente aqueles relacionados ao clima, que afetaram a atividade biológica, bem como do volume de chuvas precipitadas em cada cultivo.

As concentrações de $\mathrm{P}, \mathrm{K}$, Ca e Mg nos sedimentos da enxurrada foram expressivamente maiores do que as da água (Quadro 2), concordando com os dados de Pote et al. (1996), Gascho et al. (1998), Hernani et al. (1997) e Schick et al. (2000b), devido ao fato de que esses elementos, em especial o $\mathrm{P}$, são preferencialmente adsorvidos pelos sedimentos. Em se tratando do P, a concentração nos sedimentos foi 3,2 vezes maior na semeadura direta do que no preparo convencional, concordando com Soileau et al. (1994), e, para o K, essa diferença foi de 1,8 vez; Schick et al. (2000b) encontraram no mesmo experimento diferenças de 2,5 vezes para o $\mathrm{P}$ e de 1,6 vez para o $\mathrm{K}$, também explicadas pelas maiores concentrações desses elementos na camada superficial do solo, pelas mesmas razões apresentadas quando da discussão das concentrações desses elementos na água da enxurrada. Além disso, os sedimentos perdidos por erosão da semeadura direta provavelmente foram coloidais na sua maioria e, portanto, com maior capacidade de adsorção de elementos químicos do que os do preparo convencional, provavelmente não-coloidais na sua maioria. Pequenas variações, comparando semeadura direta e preparo convencional, também ocorreram com as concentrações de $\mathrm{Ca}$ e $\mathrm{Mg}$ nos sedimentos da enxurrada, como verificado na água.

As perdas de $\mathrm{P}$ por erosão hídrica foram relativamente baixas nos sistemas de manejo do solo (Quadro 3), sendo pouco influenciadas pelo tipo de preparo, confirmando observação de Schick et al. (2000b) em trabalho desenvolvido sobre esse mesmo experimento. Baixas quantidades de $\mathrm{P}$ perdidas por erosão hídrica também foram constatadas por Soileau et al. (1994), Martínez-Casanovas \& Ramos (2004), Ibáñez et al. (2004) e Bertol et al. (2004b). O comportamento das perdas de $\mathrm{P}$ foi diferente do das perdas de água e de solo, as quais, principalmente as de solo, foram fortemente influenciadas pelo manejo (Quadro 1), confirmando os dados de Schick et al. (2000a) obtidos nesse mesmo experimento. A semeadura direta reduziu as perdas de $\mathrm{P}$ em apenas $7 \%$ em relação ao preparo de solo convencional, na 
Quadro 2. Concentrações de P, K, Ca e Mg na água e de P disponível e K, Ca e Mg trocáveis nos sedimentos de enxurrada, em três sistemas de manejo do solo e 11 anos de cultivo

\begin{tabular}{|c|c|c|c|c|c|c|c|c|c|c|c|c|}
\hline \multirow{2}{*}{ Ano agrícola } & \multicolumn{3}{|c|}{$\mathbf{P}$} & \multicolumn{3}{|c|}{$\mathbf{K}$} & \multicolumn{3}{|c|}{$\mathbf{C a}$} & \multicolumn{3}{|c|}{ Mg } \\
\hline & $\mathrm{PC}$ & $\mathbf{P M}$ & SD & PC & $\mathbf{P M}$ & SD & $\mathbf{P C}$ & $\mathbf{P M}$ & SD & $\mathbf{P C}$ & PM & SD \\
\hline & \multicolumn{12}{|c|}{$\mathrm{Na}$ água de enxurrada, $\mathrm{mg} \mathrm{L}^{-1}$} \\
\hline $1992 / 1993$ & 0,07 & 0,20 & 0,57 & 26,0 & 21,6 & 50,8 & 2,36 & 3,93 & 2,03 & 1,46 & 0,72 & 0,95 \\
\hline $1993 / 1994$ & 0,11 & 0,21 & 0,15 & 15,9 & 20,0 & 48,6 & 1,05 & 1,92 & 0,87 & 0,87 & 1,60 & 0,73 \\
\hline 1994/1995 & 0,11 & 0,06 & 0,11 & 49,0 & 60,6 & 69,5 & 5,07 & 4,91 & 4,18 & 2,94 & 2,97 & 2,48 \\
\hline $1995 / 1996$ & 0,06 & 0,24 & 0,21 & 37,5 & 40,1 & 57,4 & 3,46 & 4,01 & 3,04 & 1,95 & 1,93 & 1,59 \\
\hline $1996 / 1997$ & 0,24 & 0,49 & 0,60 & 3,6 & 4,8 & 7,2 & 6,73 & 6,63 & 5,64 & 3,18 & 3,24 & 2,58 \\
\hline $1997 / 1998$ & 0,40 & 0,48 & 0,74 & 3,9 & 6,6 & 13,2 & 6,80 & 6,20 & 7,10 & 3,45 & 3,20 & 4,50 \\
\hline $1998 / 1999$ & 0,19 & 0,38 & 0,64 & 16,2 & 19,5 & 29,0 & 5,92 & 5,07 & 4,31 & 2,88 & 3,04 & 2,52 \\
\hline $1999 / 2000$ & 0,20 & 0,57 & 0,61 & 5,2 & 10,7 & 9,9 & 5,77 & 6,41 & 4,14 & 4,24 & 4,10 & 2,99 \\
\hline $2000 / 2001$ & 0,03 & 0,24 & 0,80 & 4,4 & 6,5 & 10,0 & 5,90 & 4,95 & 4,40 & 3,80 & 3,45 & 2,90 \\
\hline $2001 / 2002$ & 0,47 & 0,71 & 1,10 & 10,7 & 11,6 & 18,4 & 7,40 & 5,48 & 5,13 & 3,27 & 2,40 & 2,37 \\
\hline $2002 / 2003$ & 0,35 & 0,70 & 1,67 & 4,1 & 7,3 & 9,7 & 5,43 & 7,34 & 6,24 & 2,71 & 4,49 & 2,88 \\
\hline Média & 0,20 & 0,39 & 0,65 & 16,0 & 19,0 & 29,4 & 5,08 & 5,17 & 4,28 & 2,80 & 2,83 & 2,41 \\
\hline \multirow[t]{2}{*}{ DP } & 0,14 & 0,21 & 0,43 & 14,7 & 16,4 & 21,8 & 1,89 & 1,45 & 1,72 & 0,96 & 1,05 & 0,99 \\
\hline & \multicolumn{12}{|c|}{ Nos sedimentos da erosão,mg $\mathrm{dm}^{-3}$} \\
\hline $1992 / 1993$ & 29 & 57 & 116 & 312 & 410 & 471 & 690 & 810 & 950 & 234 & 234 & 252 \\
\hline 1993/1994 & 64 & 84 & 118 & 457 & 530 & 714 & 853 & 892 & 860 & 402 & 446 & 405 \\
\hline $1994 / 1995$ & 40 & 39 & 46 & 238 & 380 & 293 & 754 & 820 & 790 & 295 & 325 & 330 \\
\hline $1995 / 1996$ & 40 & 63 & 58 & 306 & 421 & 374 & 601 & 655 & 640 & 238 & 265 & 248 \\
\hline $1996 / 1997$ & 58 & 101 & 175 & 220 & 307 & 324 & 738 & 845 & 838 & 290 & 314 & 339 \\
\hline $1997 / 1998$ & 33 & 65 & 128 & 283 & 403 & 505 & 817 & 919 & 877 & 293 & 304 & 332 \\
\hline $1998 / 1999$ & 42 & 67 & 159 & 290 & 689 & 752 & 788 & 749 & 698 & 317 & 372 & 436 \\
\hline $1999 / 2000$ & 27 & 99 & 172 & 228 & 466 & 587 & 808 & 850 & 865 & 391 & 392 & 336 \\
\hline $2000 / 2001$ & 17 & 41 & 81 & 231 & 425 & 587 & 805 & 830 & 730 & 318 & 344 & 366 \\
\hline $2001 / 2002$ & 18 & 34 & 53 & 287 & 387 & 547 & 610 & 825 & 675 & 339 & 372 & 379 \\
\hline $2002 / 2003$ & 47 & 127 & 237 & 286 & 400 & 598 & 630 & 873 & 934 & 177 & 274 & 312 \\
\hline Média & 38 & 71 & 122 & 285 & 438 & 523 & 736 & 824 & 805 & 299 & 331 & 340 \\
\hline DP & 14 & 28 & 57 & 63 & 95 & 142 & 86 & 68 & 101 & 63 & 59 & 55 \\
\hline
\end{tabular}

PC: preparo convencional; PM: preparo mínimo; SD: semeadura direta; DP: desvio-padrão.

média dos valores anuais. Isso pode ser explicado pela maior concentração deste elemento, principalmente nos sedimentos da erosão, mas também na água de enxurrada, da semeadura direta (Quadro 2). Assim, os dados demonstram que, em termos de prejuízos financeiros decorrentes das perdas de nutrientes, eles foram baixos e, em ambos os sistemas de manejo do solo, comportaram-se de maneira praticamente igual. Nesse caso, o preparo mínimo foi o tratamento mais eficaz, reduzindo a perda de $\mathrm{P}$ em $13 \%$ em relação à semeadura direta e em 20 \% em relação ao preparo convencional, diferenças essas importantes se consideradas em relação àquela entre a semeadura direta e o preparo convencional (7 \%).

As perdas de K (Quadro 3) foram relativamente altas nos sistemas de manejo do solo, apresentando comportamento mais similar ao ocorrido com as perdas de água e solo (Quadro 2) do que ocorrera no caso do $\mathrm{P}$, ou seja, menores perdas de $\mathrm{K}$ na semeadura direta do que no preparo convencional, tendo sido intermediárias no preparo mínimo, conforme também verificado por Schick et al. (2000b). Neste caso, a semeadura direta reduziu a perda deste elemento em $32 \%$ em relação ao preparo convencional, estando de acordo, portanto, com a redução das perdas de água e solo nesse sistema (Quadro 1) e, também, de acordo com a maior concentração de $\mathrm{K}$ na água e nos sedimentos da enxurrada na semeadura direta do que no preparo convencional (Quadro 2). Verifica-se, assim, que a semeadura direta apresentou maior eficácia de redução das perdas de $\mathrm{K}$ do que de $\mathrm{P}$, em relação ao preparo convencional, de acordo com o que constataram também Schick et al. (2000b) e Bertol et al. (2004b), podendo, por isso, ser considerada mais conservacionista para aquele elemento do que para este.

As perdas de $\mathrm{Ca}$ e $\mathrm{Mg}$ foram relativamente altas em todos os tratamentos, tendo sido fortemente influenciadas pelo sistema de manejo, conforme também constatado por Schick et al. (2000b); foi mantida, ainda, a proporção de perdas desses elementos de aproximadamente 2:1, na média dos anos de cultivo (Quadro 3). Na média desses dois elementos, a semeadura direta reduziu suas perdas por erosão 
Quadro 3. Quantidades totais de P, K, Ca e Mg perdidas por erosão hídrica (água+sedimentos de enxurrada), em três sistemas de manejo do solo e 11 anos de cultivo

\begin{tabular}{|c|c|c|c|c|c|c|c|c|c|c|c|c|}
\hline \multirow{2}{*}{ Ano agrícola } & \multicolumn{3}{|c|}{$\mathbf{P}$} & \multicolumn{3}{|c|}{$\mathbf{K}$} & \multicolumn{3}{|c|}{$\mathrm{Ca}$} & \multicolumn{3}{|c|}{ Mg } \\
\hline & $\mathrm{PC}$ & $\mathbf{P M}$ & SD & $\mathbf{P C}$ & PM & SD & PC & $\mathbf{P M}$ & SD & $\mathbf{P C}$ & PM & SD \\
\hline & & & & & & $-\mathrm{g}$ ha & $\mathrm{ano}^{-1}$ & & & & & \\
\hline $1992 / 1993$ & 145 & 310 & 679 & 25.257 & 24.626 & 53.731 & 4.655 & 5.804 & 2.767 & 2.188 & 1.217 & 1.167 \\
\hline 1993/1994 & 471 & 366 & 122 & 16.092 & 13.022 & 14.391 & 4.591 & 2.174 & 488 & 2.620 & 1.645 & 339 \\
\hline $1994 / 1995$ & 37 & 60 & 22 & 4.980 & 14.823 & 3.351 & 716 & 1.436 & 268 & 388 & 1.026 & 147 \\
\hline $1995 / 1996$ & 269 & 498 & 98 & 62.476 & 44.252 & 11.753 & 7.945 & 6.742 & 1.236 & 4.056 & 3.032 & 561 \\
\hline $1996 / 1997$ & 1.860 & 1.189 & 1.769 & 20.572 & 11.973 & 17.916 & 43.214 & 16.581 & 14.610 & 18.774 & 8.132 & 6.478 \\
\hline 1997/1998 & 3.037 & 2.291 & 3.362 & 28.604 & 27.140 & 45.492 & 54.058 & 30.746 & 28.843 & 30.375 & 14.276 & 16.636 \\
\hline $1998 / 1999$ & 1.372 & 560 & 152 & 59.870 & 23.486 & 6.481 & 25.358 & 7.535 & 981 & 10.999 & 4.191 & 580 \\
\hline $1999 / 2000$ & 404 & 511 & 538 & 19.954 & 12.101 & 8.934 & 33.250 & 14.076 & 8.021 & 23.308 & 9.524 & 5.397 \\
\hline $2000 / 2001$ & 150 & 659 & 1.317 & 19.507 & 17.437 & 19.466 & 29.735 & 14.988 & 9.422 & 16.934 & 9.616 & 5.196 \\
\hline $2001 / 2002$ & 1.302 & 1.509 & 1.189 & 16.550 & 12.295 & 8.873 & 18.727 & 10.144 & 4.198 & 7.626 & 4.401 & 1.955 \\
\hline $2002 / 2003$ & 1.197 & 269 & 253 & 9.892 & 2.250 & 1.193 & 32.386 & 3.225 & 697 & 8.199 & 1.623 & 316 \\
\hline Média & 931 & 747 & 864 & 25.796 & 18.491 & 17.416 & 23.149 & 10.314 & 6.503 & 11.406 & 5.335 & 3.525 \\
\hline
\end{tabular}

PC: preparo convencional; PM: preparo mínimo; SD: semeadura direta.

hídrica em $71 \%$, em relação ao preparo convencional, ou seja, aproximadamente a mesma proporção da média de redução das perdas de água e solo (57\% de redução na perda de água e 88 \% de redução na perda de solo - Quadro 1). Assim, pode-se dizer que as perdas de $\mathrm{Ca}$ e $\mathrm{Mg}$ estiveram fortemente relacionadas com as perdas de água e solo e pouco relacionadas com as concentrações de tais elementos nos sedimentos da erosão e na água de enxurrada (Quadro 2). Dessa forma, verifica-se que a semeadura direta apresentou alta eficácia de redução das perdas de $\mathrm{Ca}$ e $\mathrm{Mg}$ e, por isso, pode ser considerada um sistema de manejo conservacionista, comparada ao preparo convencional. Do mesmo modo como ocorrera com o K, o preparo mínimo comportou-se de maneira intermediária aos demais sistemas de manejo do solo em relação às perdas de Ca e Mg.

As variações verificadas nas perdas de $\mathrm{P}$ disponível e K, Ca e Mg trocáveis nos anos de cultivo foram normais, principalmente de acordo com as variações nas perdas de água e solo (Quadro 1) e, ainda, nas concentrações desses elementos na água e nos sedimentos de enxurrada (Quadro 2).

A quantidade de $\mathrm{P}$ disponível perdido por erosão hídrica foi expresso como $\mathrm{P}_{2} \mathrm{O}_{5}$; o $\mathrm{K}$ trocável, como $\mathrm{K}_{2} \mathrm{O}$; e o $\mathrm{Ca}$ e $\mathrm{Mg}$ trocáveis, como $\mathrm{CaO}+\mathrm{MgO}$. Estas formas, por sua vez, foram convertidas respectivamente nos fertilizantes superfosfato triplo e cloreto de potássio e em calcário. As perdas de $\mathrm{P}$ na forma de superfosfato triplo foram relativamente baixas e semelhantes nos distintos sistemas de manejo do solo, na média dos anos de cultivo (Quadro 4), indicando terem pouco contribuído para as perdas totais de nutriente na forma de fertilizante, em termos monetários, conforme também constatado por Freitas \& Castro (1983),
Pimentel et al. (1995), Alfsen et al. (1996) e MartínezCasanovas \& Ramos (2004). No caso do K na forma de cloreto de potássio e do $\mathrm{Ca}$ e $\mathrm{Mg}$ na forma de calcário, por outro lado, as perdas foram relativamente altas, em todos os tratamentos, na média dos anos de cultivo, o que torna essas perdas importantes do ponto de vista financeiro, concordando com os autores supracitados.

As baixas quantidades de $\mathrm{P}$ expressas na forma de superfosfato triplo e as altas quantidades de $\mathrm{K}$ na forma de cloreto de potássio e de Ca e Mg expressas em calcário, perdidas por erosão hídrica (Quadro 4), resultaram das altas quantidades de água e baixas quantidades de solo perdidas (Quadro 1), bem como da concentração de $\mathrm{P}$ disponível relativamente baixa e das concentrações de $\mathrm{K}$, Ca e Mg relativamente altas na água e nos sedimentos de enxurrada (Quadro 2). Assim, em termos financeiros, a semeadura direta reduziu em $8 \%$ a perda média anual de $\mathrm{P}$ na forma de superfosfato triplo, enquanto para o $\mathrm{K}$ na forma de cloreto de potássio e para o Ca e Mg na forma de calcário as reduções foram respectivamente de 32 e $71 \%$, em relação ao preparo convencional. Isso foi resultado da eficácia de tal sistema de manejo do solo na redução das perdas de água e, principalmente, de solo. Apesar disso, a semeadura direta não apresentou a mesma eficácia na redução das concentrações dos nutrientes na água e, principalmente, nos sedimentos de enxurrada, os quais foram expressos como fertilizantes, e calcário, refletindo-se em menores reduções no custo financeiro de tais perdas.

As perdas anuais de $\mathrm{P}$ disponível e $\mathrm{K}$, $\mathrm{Ca}$ e $\mathrm{Mg}$ trocáveis por erosão hídrica, calculadas e expressas na forma de fertilizantes e de calcário, em termos monetários, foram relativamente altas (Quadro 4), 
Quadro 4. Quantidades totais de P expresso na forma de superfosfato triplo, K, na forma de cloreto de potássio, e Ca e Mg, na forma de calcário, perdidas por erosão hídrica (água + sedimentos de enxurrada) e o valor monetário das referidas perdas (US\$1,00 $=R \$ 2,50$, em 25/10/2005), em três sistemas de manejo do solo e 11 anos de cultivo

\begin{tabular}{|c|c|c|c|c|c|c|c|c|c|}
\hline \multirow{2}{*}{ Ano agrícola } & \multicolumn{3}{|c|}{ P (Superfosfato triplo) } & \multicolumn{3}{|c|}{ K (Cloreto de potássio) } & \multicolumn{3}{|c|}{ Ca e Mg (Calcário) } \\
\hline & $\mathbf{P C}$ & PM & SD & $\mathbf{P C}$ & $\mathbf{P M}$ & SD & PC & PM & SD \\
\hline $1992 / 1993$ & 0,8 & 1,7 & 3,7 & 50,7 & 49,5 & 107,9 & 26,8 & 27,5 & 15,4 \\
\hline $1993 / 1994$ & 2,6 & 2,0 & 0,7 & 32,3 & 26,2 & 28,9 & 28,2 & 15,0 & 3,2 \\
\hline $1994 / 1995$ & 0,2 & 0,3 & 0,1 & 10,0 & 29,7 & 6,7 & 4,3 & 9,7 & 1,6 \\
\hline $1995 / 1996$ & 1,5 & 2,7 & 0,5 & 125,5 & 88,9 & 23,6 & 47,1 & 38,3 & 7,0 \\
\hline $1996 / 1997$ & 10,1 & 6,5 & 9,6 & 41,3 & 23,4 & 36,0 & 243,1 & 96,9 & 82,7 \\
\hline $1997 / 1998$ & 16,6 & 12,5 & 18,3 & 57,5 & 54,5 & 91,4 & 331,1 & 170,5 & 178,3 \\
\hline $1998 / 1999$ & 7,5 & 3,1 & 0,8 & 120,2 & 47,2 & 13,0 & 142,6 & 46,0 & 6,1 \\
\hline $1999 / 2000$ & 2,2 & 2,8 & 2,9 & 40,1 & 24,3 & 17,9 & 221,8 & 92,5 & 52,6 \\
\hline $2000 / 2001$ & 0,8 & 3,6 & 7,2 & 39,2 & 35,0 & 39,1 & 183,0 & 96,5 & 57,3 \\
\hline $2001 / 2002$ & 7,1 & 8,2 & 6,5 & 33,2 & 24,7 & 17,8 & 103,3 & 57,0 & 24,1 \\
\hline $2002 / 2003$ & 6,5 & 1,5 & 1,4 & 19,9 & 4,5 & 2,4 & 159,1 & 19,0 & 4,0 \\
\hline Média/ano & 5,1 & 4,1 & 4,7 & 51,8 & 37,1 & 35,0 & 135,5 & 60,8 & 39,3 \\
\hline $\begin{array}{l}\text { Média/ano/ } \\
\text { manejo }\end{array}$ & 1,65 & 1,33 & 1,52 & 16,99 & 12,17 & 11,48 & 6,30 & 2,83 & 1,83 \\
\hline Média/ano & \multicolumn{2}{|l|}{$\mathrm{P}(\mathrm{SFT})=1,50$} & & \multicolumn{3}{|c|}{$\mathrm{K}(\mathrm{KCl})=13,55$} & \multicolumn{3}{|c|}{ Ca e $\mathrm{Mg}$ (Calcário) = 3,65 } \\
\hline Total/ano & & $\mathrm{PC}$ & & & $\mathrm{PM}$ & & & SD & \\
\hline \multicolumn{2}{|c|}{$\begin{array}{l}\mathrm{P}(\mathrm{SFT})+\mathrm{K}(\mathrm{KCL})+\mathrm{Ca} \text { e } \\
\mathrm{Mg} \text { (Calcário) }\end{array}$} & 24,94 & & & 16,33 & & & 14,83 & \\
\hline
\end{tabular}

embora menores do que aquelas estimadas por Freitas \& Castro (1983), Pimentel et al. (1995), Alfsen et al. (1996) e Martínez-Casanovas \& Ramos (2004). Na semeadura direta, a perda total de $\mathrm{P}$ disponível, expressa como superfosfato triplo, foi equivalente a $10,2 \%$ das perdas totais dos elementos P, K, Ca e $\mathrm{Mg}$, expressas como fertilizantes e calcário, enquanto as perdas totais de $\mathrm{K}$ trocável, expresso como cloreto de potássio, e de Ca e Mg trocáveis, expressos como calcário, corresponderam, respectivamente, a 77,6 e $12,2 \%$. No preparo mínimo, as perdas desses elementos corresponderam, respectivamente, a 8,1\% para o superfosfato triplo, $74,6 \%$ para o cloreto de potássio e $17,3 \%$ para o calcário, enquanto no preparo convencional as referidas perdas corresponderam, respectivamente, a 6,6, 68,1 e 25,3\%. Portanto, destaca-se a tendência dos sistemas conservacionistas de manejo do solo (semeadura direta e preparo mínimo) de ocasionarem perdas mais elevadas de $\mathrm{P}$ disponível, expresso como superfosfato triplo, e de $\mathrm{K}$ trocável, expresso como cloreto de potássio, do que de Ca e Mg trocáveis, expressos como calcário, em termos de valor monetário. O preparo convencional, por outro lado, tendeu a apresentar perdas mais elevadas de Ca e $\mathrm{Mg}$ na forma de calcário do que de $\mathrm{P}$ na forma de superfosfato triplo e de $\mathrm{K}$ na forma de cloreto de potássio, em termos de valor monetário. No entanto, para um mesmo elemento expresso na forma de um fertilizante, ou para um mesmo elemento expresso na forma de calcário, as diferenças relativas foram muito pequenas entre os sistemas de manejo do solo avaliados, concordando, em parte, com Freitas \& Castro (1983).

As perdas médias anuais de $\mathrm{P}$ e $\mathrm{K}$ expressos como fertilizantes e de Ca e Mg expressos como calcário, em termos monetários, totalizaram 18,70 US $\$$ ha $^{-1}$ nos três sistemas de manejo do solo estudados (Quadro 4), dos quais 8,0\% (1,50 US\$ ha $\left.{ }^{-1}\right)$ corresponderam ao $\mathrm{P}$ na forma de superfosfato triplo, $72,4 \%\left(13,55 \mathrm{US} \$ \mathrm{ha}^{-1}\right)$ ao $\mathrm{K}$ na forma de cloreto de potássio e 19,6\% (3,65 US\$ ha $\left.{ }^{-1}\right)$ ao Ca e Mg na forma de calcário. Portanto, em termos monetários, o K, na forma de cloreto de potássio, foi o elemento que mais contribuiu para a perda total de adubos por erosão hídrica, conforme constatado também por Freitas \& Castro (1983). Assim, é importante estabelecer formas de controle de enxurrada nas lavouras. Esse controle é feito aumentando a infiltração de água no solo e adotando o cultivo em contorno associado a terraços de absorção. Isso diminui os prejuízos financeiros decorrentes das perdas de nutrientes na forma de fertilizantes e de calcário por erosão hídrica, bem como controla os prováveis enriquecimento e contaminação ambiental que estes provocam fora do local de origem da erosão. 
Em termos de fertilizantes e de calcário, a semeadura direta foi o tratamento mais eficaz na redução das perdas totais anuais dos nutrientes $P, K$, Ca e Mg, com diminuição de 41 \% no valor monetário das perdas, em relação ao preparo convencional, e de 9 \% em relação ao preparo mínimo (Quadro 4). Isso evidencia a eficácia da semeadura direta na redução das perdas de nutrientes das plantas por erosão hídrica, em relação ao preparo convencional, embora, em termos quantitativos, as perdas ocorridas na semeadura direta não devam ser desprezadas.

Além do aspecto financeiro, há que se considerar ainda o aspecto ambiental relativo ao efeito das perdas de nutrientes por erosão hídrica nos locais de depósito destes (Daniel et al., 1994; Favaretto, 2002). Nas lavouras adubadas, especialmente naquelas em que os adubos e o calcário são aplicados em superfície ou próximo dela, como na semeadura direta, ou naquelas em que estes são semi-incorporados ao solo, como nos demais preparos conservacionistas, a água e os sedimentos perdidos por erosão hídrica podem apresentar altas concentrações de nutrientes, como constatado neste trabalho (Quadro 1). Os solos e as águas superficiais, no Brasil, apresentam baixa fertilidade em condições naturais. Em decorrência disso, e considerando que as enxurradas são em geral enriquecidas com nutrientes, como demonstram os dados aqui apresentados, a água e os sedimentos da erosão hídrica podem causar grande impacto ambiental nos locais de depósito destes, fora do local de origem da erosão, como constatado por Daniel et al. (1994).

\section{CONCLUSÕES}

1. O valor monetário correspondente ao total dos nutrientes $\mathrm{P}$ disponível, expresso na forma de superfosfato triplo, K trocável, na forma de cloreto de potássio, e Ca e Mg trocáveis, na forma de calcário, perdidos anualmente por erosão hídrica, foi relativamente elevado, independentemente do sistema de manejo do solo.

2. A semeadura direta e o preparo mínimo do solo comportaram-se de maneira semelhante em termos de valor monetário de $\mathrm{P}$ disponível, expresso na forma de superfosfato triplo, $\mathrm{K}$ trocável, na forma de cloreto de potássio, e Ca e Mg trocáveis, na forma de calcário, perdidos anualmente por erosão hídrica, em cujos tratamentos tais perdas foram expressivamente menores do que aquelas verificadas no preparo convencional.

3. $\mathrm{O}$ valor monetário de $\mathrm{K}$ trocável expresso na forma de cloreto de potássio perdido anualmente por erosão hídrica foi equivalente a, aproximadamente, 2,6 vezes aquele representado pelo somatório das perdas de $\mathrm{P}$ disponível na forma de superfosfato triplo e de Ca e Mg trocáveis na forma de calcário, na média dos sistemas de manejo do solo.

\section{LITERATURA CITADA}

ALFSEN, K.H.; De FRANCO, M.A.; GLOMSRØD, S. \& JOHNSEN, T. The cost of soil erosion in Nicaragua. Ecol. Econ., 16:129-145, 1996.

BERTOL, I.; ALBUQUERQUE, J.A.; LEITE, D.; AMARAL, A.J. \& ZOLDAN JR., W.A. Propriedades físicas do solo sob preparo convencional e semeadura direta em rotação e sucessão de culturas, comparadas às do campo nativo. R. Bras. Ci. Solo, 28:155-163, 2004a.

BERTOL, I.; GUADAGNIN, J.C.; CASSOL, P.C.; AMARAL, A.J. \& BARBOSA, F.T. Perdas de fósforo e potássio por erosão hídrica em um Inceptisol sob chuva natural. R. Bras. Ci. Solo. 28:485-494, 2004b.

BERTOL, I.; COGO, N.P. \& LEVIEN, R. Erosão hídrica em diferentes preparos do solo logo após as colheitas de milho e trigo, na presença e na ausência dos resíduos culturais. R. Bras. Ci. Solo, 21:409-418, 1997.

BERTOL, I.; MELLO, E.L.; GUADAGNIN, J.C.; ZAPAROLLI, A.L.V. \& CARRAFA, M.R. Nutrient losses by water erosion. Sci. Agron., 60:581-586, 2003.

COGO, N.P. Effect of residue cover, tillage induced roughness, and slope length on erosion and related parameters. West Lafayette, Purdue University, 1981. 346p. (Tese de Doutorado)

COGO, N.P. Uma contribuição à metodologia de estudo das perdas de erosão em condições de chuva natural. I. Sugestões gerais, medição dos volumes, amostragem e quantificação de solo e água da enxurrada (1a aproximação). In: ENCONTRO NACIONAL DE PESQUISA SOBRE CONSERVAÇÃO DO SOLO, 2., Passo Fundo, 1978. Anais. Passo Fundo, EMBRAPACNPT, 1978. p.75-98.

COGO, N.P.; FOSTER, G.R. \& MOLDENHAUER, W.C. Flow rates-soil erosion relationships as affected by wheat residue cover: an attempt to define slope-length limits for conservation tillage. R. Bras. Ci. Solo, 20:475-483, 1996.

DANIEL, T.C.; SCHARPLEY, A.N.; EDWARDS, D.R.; WEDEPOHL, R. \& LEMUNYON, J.L. Minimizing surface water eutrophication from agriculture by phosphorus management. J. Soil Water Conserv., 40:30-38, 1994.

DULEY, F.L. Surface factor affecting the rate of intake of water by soils. Soil Sci. Soc. Am. Proc., 4:60-64, 1939.

FAVARETTO, N. Gypsum amendment and exchangeable calcium and magnesium related to water quality and plant nutrition. West Lafayette, Purdue University, 2002. 150p.

FOSTER, G.R.; JOHNSON, C.B. \& MOLDENHAUER, W.C. Critical slope lengths for unanchored cornstalk and wheat straw residue. Trans. Am. Soc. Agric. Eng., 25:935-939, 947, 1982

FREITAS, P.L. \& CASTRO, A.F. Estimativas das perdas de solo e nutrientes por erosão no Estado do Paraná. B. Inf. SBCS, 8:43-52, 1983.

GASCHO, G.J.; WAUCHOPE, R.D. \& DAVIS, J.G. Nitratenitrogen, soluble, and bioavailable phosphorus runoff from simulated rainfall after fertilizer application. Soil Sci, Soc. Am. J., 62:1711-1718, 1998. 
GUADAGNIN, J.C.; BERTOL, I.; CASSOL, P.C. \& AMARAL, A.J. Perdas de solo, água e nitrogênio por erosão hídrica em diferentes sistemas de manejo. R. Bras. Ci. Solo, 29:277-286, 2005.

HERNANI, L.C.; SALTON, J.C.; FABRÍCIO, A.C.; DEDECEK, R. \& ALVES JR., M. Perdas por erosão e rendimentos de soja e de trigo em diferentes sistemas de preparo de um Latossolo Roxo de Dourados (MS). R. Bras. Ci. Solo, 21:667-676, 1997.

HUDSON, N.W. Soil conservation. Ithaca, Cornell University Press, 1995. 324p.

IBÁÑEZ, A.; MARTÍNEZ. C.; RAMOS, M.C. \& MARTÍNEZCASANOVAS, J.A. Effects of composted cattle manure on erosion rates and nutrient losses. EUROSOIL, 2004 Freiburg, Germany. Abstracts. Freiburg,CD-ROOM.

LANGDALE, G.W.; LEONARD, R.A. \& THOMAS, A.W Conservation practice effects on phosphorus losses from Southern Piedmont watersheds. J. Soil Water Conserv., 40:157-160, 1985.

MARTÍNEZ-CASASNOVAS, J.A. \& RAMOS, M.C. The cost of soil erosion in vineyard fields of the Penedès - Anoia Region (NE Spain). EUROSOIL, 2004, Freiburg. Abstracts. Freiburg,, 2004.CD-ROOM.

McINTYRE, D.S. Permeability measurements of soil crusts formed by raindrop impact. Soil Sci., 85:185-189, 1958.

MELLO, E.L.; BERTOL, I.; ZAPAROLLI, A.L.V. \& CARRAFA, M.R. Perdas de solo e água em diferentes sistemas de manejo de um Nitossolo Háplico submetido à chuva simulada. R. Bras. Ci. Solo, 27:901-909, 2003.

MORAIS, L.F.B. \& COGO, N.P. Comprimentos críticos de rampa para diferentes manejos de resíduos culturais em sistema de semeadura direta em um Argissolo Vermelho na Depressão Central-RS. R. Bras. Ci. Solo, 25:1.041-1.051, 2001.
PIMENTEL, D.; HARVEY, C.; RESOSUDARMO, P.; SINCLAIR, K.; KURZ, D.; McNAIR, M.; CRIST, S.; SHPRITZ, L.; FITTON, L.; SAFFOURI, R. \& BLAIR, R. Environmental and economic costs of soil erosion and conservation benefits. Sci., 267:1.117-1.123, 1995.

POTE, D.H.; DANIEL, T.C. \& SHARPLEY, A.M. Relating extractable soil phosphorus to phosphorus losses in runoff. Soil Sci. Soc. Am. J., 60:855-859, 1996.

SCHICK, J.; BERTOL, I.; BALBINOT JR., A.A. \& BATISTELA, O. Erosão hídrica em Cambissolo Húmico alumínico submetido a diferentes sistemas de preparo e cultivo do solo: II. Perdas de nutrientes e carbono orgânico. R. Bras. Ci. Solo, 24:437-447, 2000b.

SCHICK, J.; BERTOL, I.; BATISTELA, O. \& BALBINOT JR., A.A. Erosão hídrica em Cambissolo Húmico alumínico submetido a diferentes sistemas de preparo e cultivo do solo: I. Perdas de solo e água. R. Bras. Ci. Solo, 24:427436, 2000a.

SEGANFREDO, M.L.; ELTZ, F.L.F. \& BRUM, A.C.R. Perdas de solo, água e nutrientes por erosão em sistemas de culturas em plantio direto. R. Bras. Ci. Solo, 21:287-291, 1997.

SOILEAU, J.M.; TOUCHTON, J.T.; HAJEK, B.F. \& YOO, K.H. Sediment, nitrogen, and phosphorus runoff with conventional - and conservation- tillage cotton in small watershed. J. Soil Water Conserv., 49:82-89, 1994.

STOLTENBERG, N.L. \& WHITE, J.L. Selective loss of plant nutrients by erosion. Soil Sci. Proc., 17:406-410, 1953.

TEDESCO, M.J.; GIANELLO, C.; BISSANI, C.A.; BOHNEN, H. \& VOLKWEISS, S.J. Análise de solos, plantas e outros materiais. 2.ed. Porto Alegre, Universidade Federal do Rio Grande do Sul, 1995. 174p.

WISCHMEIER, W.H. \& SMITH, D.D. Predicting rainfall erosion losses: a guide to conservation planning. Washington, USDA, 1978. 58p. (Agricultural Handbook, 537) 